\title{
THE INVESTIGATION OF THE STRENGTH REDUCTION FACTOR IN PREDICTING THE SHEAR STRENGTH
}

\author{
Guray Arslan, Sema Noyan Alacali, Ali Sagiroglu \\ Yildiz Technical University, Department of Civil Engineering,Esenler, Istanbul, Turkey \\ e-mail: gurayarslan@gmail.com; semanoyal@gmail.com; alisagirogluktu@gmail.com
}

\begin{abstract}
Design codes propose to restrict the nominal probability of failure within specific target structural reliability levels using a load factor and a strength reduction factor. In the current ACI318 Code, the strength reduction factor varies from 0.65 to 0.90 , and the value considered in predicting the shear strength equals to 0.75 . In this study, the change in the strength reduction factor in predicting the shear strength according to ACI318 has been investigated for different coefficients of variation of concrete compressive strength by using the first-order second moment approach, and the strength reduction factor is proposed for the target values of failure probability.
\end{abstract}

Keywords: reinforced concrete, beam, shear strength, reduction factor, target reliability

\section{Introduction}

The safety of a structure can be explained as the probability that the structure will perform its purposes throughout its design lifetime. In order to provide certain reliability levels for structures, design codes use safety factors. Partial safety factors are to be evaluated for a given target reliability index $(\beta)$. The value of $\beta$ depends on the relative consequences of failure and the relative costs of safety measures. The range of $\beta$ for flexural strength of reinforced concrete (RC) beams designed according to ACI318 was investigated by Mirza (1996). The resulting value of $\beta$ is 3.1 (range 2.5-3.9). The target values of $\beta$ were set in the study of Mirza (1996) at 3.0 and 3.25 for columns exhibiting tension and compression failures, respectively. MacGregor (1983) took as $\beta=2.5-3$ for tension failures and $\beta=3-3.5$ for compression failures. A higher value of $\beta$ was assigned to members displaying compression failure, reflecting the increased danger due to sudden, brittle behavior of such members at the failure load.

Beck et al. (2009) and Oliveira et al. (2008) noted that the target $\beta$ of structures designed according to NBR8800 (2008) lies in the range from 2.3 to 4.5. The AS5104 (2005) and ISO2394 (1998) suggest that the lifetime target $\beta$ ranges from 3.1 to 4.3 for ultimate (strength) limit states design. According to Vrouwenvelder (2002), the central value of $\beta=4.2\left(p_{F}=1.33 \cdot 10^{-5}\right)$ should be considered as the most common design situation, and the value of $\beta=3.8\left(p_{F}=0.7 \cdot 10^{-5}\right)$ is mentioned for a reference period of 50 years in the Eurocode. The target value of $\beta$ in the studies of Hasofer and Lind (1974), Rackwitz and Fiessler (1978) and Madsen et al. (1986) was set at 4.1 .

ACI318 and ASCE/SEI (2010) are based on semi-probabilistic approaches to design (Ribeiro and Diniz, 2013). According to the study of Nowak and Szerszen (2003) that is the basis of ACI318 calibration, the target $\beta$ is 3.5 (range 3.4-3.6) for RC beams. In the ACI318 (1995), the strength reduction factor for shear is 0.85 . According to the ACI318 (2002, 2011), the strength reduction factor for shear is 0.75 . According to TS500 (2000), the contribution of concrete to shear strength is obtained by reducing diagonal cracking strength with a safety factor of 0.8 . 
A first-order second moment probabilistic analysis procedure is used to compute the strength reduction factor in predicting the shear strength of RC beams according to the current ACI318 (2011), Section 9.3. The change in the strength reduction factor against the coefficient of variation of concrete compressive strength $\left(V_{f c}\right)$ and the failure probability $\left(p_{F}\right)$ is investigated through the database of 375 shear test results collected from 36 references.

\section{Design recommendations for $\mathrm{RC}$ beams}

According to the ACI318, the nominal shear strength $\left(\nu_{n}\right)$ is derived from two components: concrete and stirrups. This relationship is given as follows

$$
\nu_{n}=\nu_{c}+\nu_{s}
$$

in which $\nu_{s}$ is the shear strength of stirrup based on yield and $\nu_{c}$ is the shear strength of concrete, respectively. The shear strength of concrete consists of four mechanisms of shear transfer identified by the ASCE-ACI426 (1973) report as follows: the uncracked portion of the concrete, vertical components of the aggregate interlocking force in the cracked portion of concrete, dowel action of the longitudinal steel, and arch action. The shear strength of RC beams is given as follows

$$
\nu_{n}=\frac{1}{6} \sqrt{f_{c}}+\rho_{w} f_{y w}
$$

in which $\rho_{w}$ is the ratio of stirrups, $f_{c}$ and $f_{y w}$ are the compressive strength of concrete and yield strength of stirrup in MPa, respectively.

In the ACI318, the strength design philosophy states that the design shear capacity of a member must exceed the shear demand as shown in Eq. (2.3)

$$
\phi \nu_{n} \geqslant \nu_{u}
$$

in which $\phi$ is the shear strength reduction factor and given as 0.75 in ACI318 (2011) and 0.85 in ACI318 (1995). In this study, the change in the strength reduction factor considered in predicting the shear strength according to the ACI318 (2011) is investigated and compared for different failure probabilities and coefficients of variation of concrete compressive strength.

\section{Reliability analysis}

\subsection{Analysis method}

In probability theory, the capacity $R$ and the load $S$ involve different basic variables. Hence the performance function, $Z=R-S=g\left(X_{1}, X_{2}, \ldots, X_{n}\right)$, contains uncertainties in all design variables. When the performance function equals to zero, $Z=0$, it is called a failure surface. The safety or reliability is defined by the condition $Z>0$ and therefore, failure by $Z<0$. The calculation of probabilities of reliability or failure requires the knowledge of the joint probability distribution of all basic variables in the performance function. However, in many cases, these probability distributions are unavailable or difficult to obtain due to general lack of data. Besides, even though distributions of the variables are known, if the performance function is highly nonlinear, the evaluation of failure probability by numerical methods is difficult (Ranganathan, 1990; Ang and Tang, 1984).

Because of these difficulties, the approximate methods for evaluation of structural reliability have been improved. In these methods, the random variables are represented by their first and 
second moments. In evaluating the first and second moments of the failure function, the first order approximation is used. That is why these methods are called first-order second moment methods. Therefore, this method is generally used by committees in calibrating codes for the evaluation of partial safety factors (Ranganathan, 1990).

\subsection{Determination of partial safety factors}

In this study, the determination of the strength reduction factor has been developed using the first-order second moment method. The strength reduction factor may be called as partial safety factor in the reliability based design. Partial safety factors are to be evaluated for a given $\beta$. At the same time, $\beta$ is the safety measure that corresponds to a given probability of failure. Hence, in the reliability based design, the problem of the partial safety factors is reverse. If $x_{i}^{*}$ is the design value of the original variable $X_{i}$, the failure surface equation is defined as

$$
g\left(x_{1}^{*}, x_{2}^{*}, \ldots, x_{n}^{*}\right)=0 \quad i=1,2, \ldots, n
$$

where $x_{i}^{*}\left(=\gamma_{i} m_{X_{i}}\right)$ is the most probable failure point on the failure surface, and the determination of $x_{i}^{*}$ requires an iterative solution. Thus, it is required to find the design point $\left(\gamma_{i} m_{X_{i}}\right)$ corresponding to the target $\beta$. The most general design format is to apply a safety factor on each of all design variables. The performance function must satisfy

$$
g\left(\gamma_{1} m_{X_{1}}, \gamma_{2} m_{X_{2}}, \ldots, \gamma_{i} m_{X_{i}}\right)=0 \quad i=1,2, \ldots, n
$$

The design point should be the most probable failure point. In the space of the reduced variates, the most probable failure point is $x_{i}^{\prime *}=-\alpha_{i}^{*} \beta$, and $\beta$ is defined as the shortest distance from the failure surface to the origin.

Sensitivity coefficient $\alpha_{i}^{*}$ is defined by as (Ang and Tang, 1984)

$$
\alpha_{i}^{*}=\frac{\partial g}{\partial X_{i}^{\prime}}\left[\sum_{i=1}^{n}\left(\frac{\partial g}{\partial X_{i}^{\prime}}\right)_{*}^{2}\right]^{-1 / 2}
$$

The partial safety factors required for a given $\beta$ are defined as $\gamma_{i}\left(=x_{i}^{*} / m_{X_{i}}\right)$. The original variables are given by $x_{i}^{*}=m_{X_{i}}\left(1-\alpha_{i}^{*} \beta V_{X_{i}}\right)$, in which $m_{X_{i}}$ and $V_{X_{i}}$ are the mean value and the variance coefficient of the original variable $X_{i}$ with normal distribution, respectively. $V_{X_{i}}$ is the ratio of standard deviation $\left(\sigma_{X_{i}}\right)$ to the mean value $\left(m_{X_{i}}\right)$. The partial safety factors are calculated as $\gamma_{i}=\left(1-\alpha_{i}^{*} \beta V_{X_{i}}\right)$.

In this study, it is assumed that the distributions of variables in the performance function are normal and lognormal. In lognormal distributions, $m_{X_{i}}$ and $\sigma_{X_{i}}$ should be replaced by the equivalent normal mean $m_{X_{i}}^{N}$ and standard deviation $\sigma_{X_{i}}^{N}$. In addition, it is also assumed that the all variables are statistically independent (Ang and Tang, 1984).

\subsection{Strength reduction factor}

The performance function $g(X)$ for the shear failure mode is expressed as

$$
g(X)=\gamma_{i} \nu_{n}-\gamma_{j} \nu_{u, e x p}
$$

in which $\nu_{n}$ is the nominal shear strength, $\nu_{u, \exp }$ is the experimental shear strength, $\gamma_{i}$ and $\gamma_{j}$ are the safety factors corresponding to the related variables. By calculating weighted averages of these factors $\left(\gamma_{i}\right)$, the strength reduction factor $\phi$, defined in Eq.(3.4) is determined. The change in the $\phi$ considered in predicting the shear strength according to the ACI318 against the different $V_{f_{c}}(0.10,0.12,0.15,0.18)$ and $p_{F}\left(10^{-7}, 10^{-6}, 10^{-5}, 10^{-4}, 10^{-3}, 10^{-2}\right)$ has been investigated by using experimental studies available in the literature. 


\section{Uncertainties of random variables}

The uncertainties included in the prediction of shear strength are modeled as random variables. Since there is no information about the measurement sensivity in the experiments, the values of the coefficient of variation taken into account in the calculations are determined by considering the previous statistical studies.

The coefficient of variation of concrete compressive strength $\left(V_{f_{c}}\right)$ under average construction quality control usually depends on the concrete strength and varies in between 0.10 and 0.21 through the literature. The $V_{f_{c}}$ was taken as 0.10 by Nowak and Szerszen (2003) and Ribeiro and Diniz (2013), 0.11 by Hao et al. (2010), 0.12 by Neves et al.(2008) and Soares et al. (2002), 0.13 by Val et al. (1997), 0.15 by Mirza (1996), Mirza et al. (1979), Mirza and MacGregor (1979a,b), 0.16 by Val and Chernin (2009) and Hosseinnezhad et al. (2000), 0.18 by Enright and Frangopol (1998) and Ramsay et al. (1979), 0.20 by Melchers (1999) and 0.21 by Ellingwood (1978).

Although the reinforcement ratios depend on the structural dimensions, they are assumed to be statistically independent from each other and from the other random structural parameters. In the study of Hao et al. (2010), it was assumed that the coefficient of variation of stirrup ratio $\left(V_{\rho_{w}}\right)$ is 0.15 , which is the value used in this study.

The coefficient of variation of reinforcement strength $\left(V_{f_{y}}\right)$ was also reported by many researchers. Slightly different values were given by different researchers, where the $V_{f_{y}}$ ranges from 0.05 to 0.15 . The $V_{f_{y}}$ was taken as 0.05 by JCSS (2000), 0.08 by Val et al. (1997), Hosseinnezhad et al. (2000) and Low and Hao (2001), 0.06 by Soares et al. (2002), 0.08-0.11 by Ostlund (1991), MacGregor et al. (1983), 0.12 by Enright and Frangopol (1998) and 0.15 by Mirza (1996), Mirza et al. (1979), Mirza and MacGregor (1979a,b). The $V_{f_{y}}$ is taken as 0.10 in the present study. In the studies of Hognestad (1951) and Mirza (1996), it was assumed that the coefficient of variation of strength due to test procedure was 0.04 , which is the value used in this study.

\section{Investigation of the strength reduction factor in predicting the shear strength}

The distributions of main properties of the beams in the database of 375 shear test results (Adebar and Collins, 1996; Anderson and Ramirez, 1989; Angelakos et al., 2001; Bahl, 1968; Bresler and Scordelis, 1961; Bresler and Scordelis, 1966; Cladera and Mari, 2005, 2007; Collins and Kuchma, 1999; Cucchiara et al., 2004; Elzanaty et al., 1986; Guralnick, 1960; Gonzalez, 2002; Haddadin et al., 1971; Johnson and Ramirez, 1989; Leonhardt and Walter, 1962; Karayiannis and Chalioris, 1999; Kong and Rangan, 1998; Krefeld and Thurston, 1966; Lee and Kim, 2008; Mattock and Wang, 1984; McGormley et al., 1996; Mphonde and Frantz, 1985; Placas and Regan, 1971; Palakas and Darwin, 1980; Rajagopalan and Ferguson, 1968; Swamy and Andriopoulos, 1974; Ozcebe et al., 1999; Roller and Russell, 1990; Sarzam and Al-Musawi, 1992; Shin et al., 1999; Tan et al., 1997; Xie et al., 1994; Yoon et al., 1996; Zararis and Papadakis, 1999; Zararis, 2003) are shown in Fig. 1. The frequency distribution of $f_{c}$ varies from $12 \mathrm{MPa}$ to $103 \mathrm{MPa}$, so covers a wide range of RC properties. In this study, the normal strength concrete (NSC) is defined as concrete having compressive strength less than $55 \mathrm{MPa}$, and high strength concrete (HSC) having compressive strength equal to or more than $55 \mathrm{MPa}$. Only $5 \%$ of the NSC beam tests (14 of 281 tests) were conducted for $f_{c} \leqslant 20 \mathrm{MPa}$ and $20 \%$ of the HSC beam tests (19 of 94 tests) were conducted for $f_{c} \geqslant 80 \mathrm{MPa}$. It can be stated that the $f_{c}$ values are not equally distributed in the range from $45 \mathrm{MPa}$ to $75 \mathrm{MPa}$. A large amount of beams is characterized by $30 \mathrm{MPa}$ for the NSC beams and $75 \mathrm{MPa}$ for the HSC beams. 

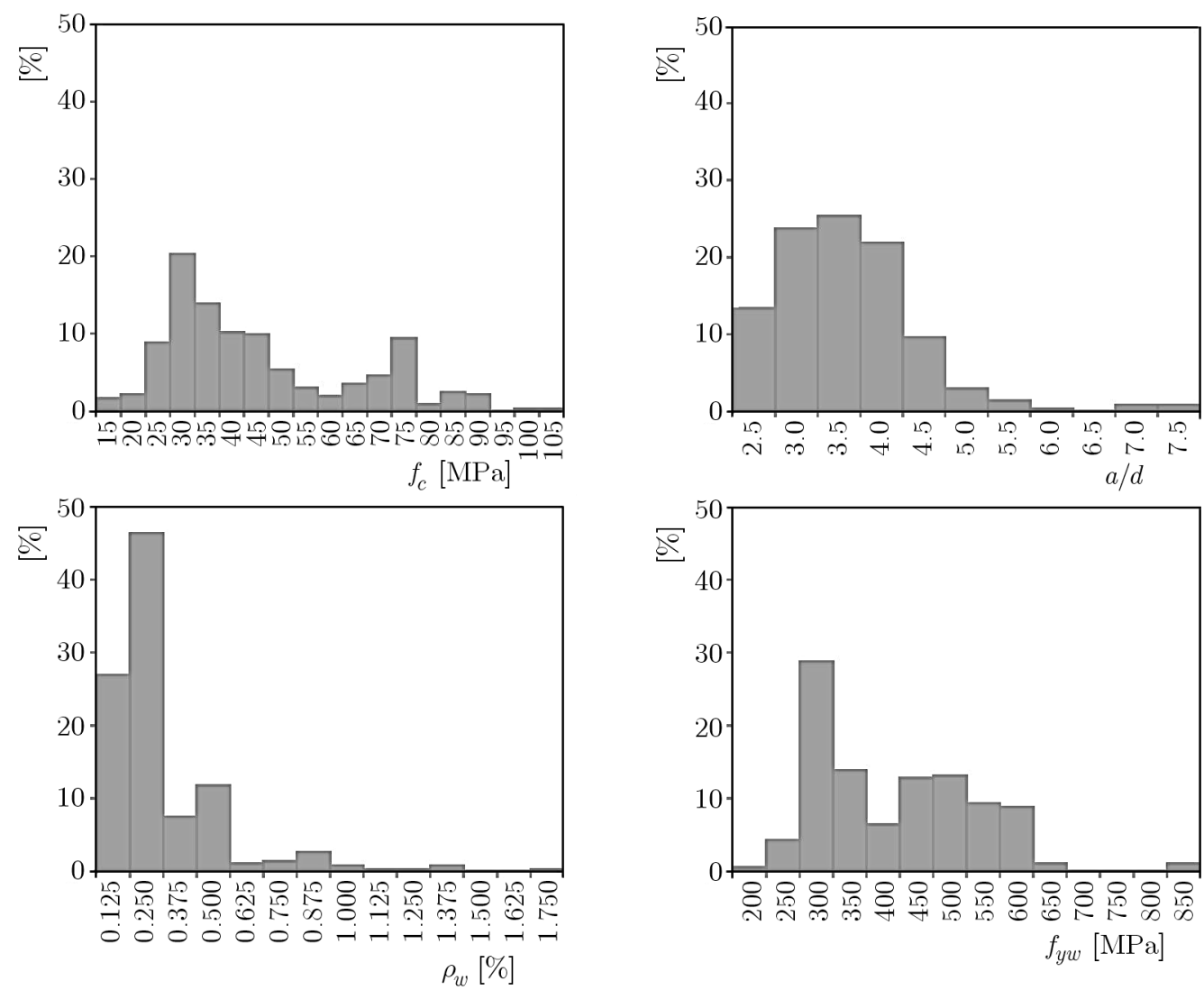

Fig. 1. Data frequency distributions: $f_{c}, a / d, \rho_{w}$ and $f_{y w}$

The frequency distribution of shear span-to-depth ratio $(a / d)$ varies from 2.5 to 7.5 . It is worth noting that $a / d$ values are not equally distributed in the range from 2.5 to 7.5 and most of the beams are characterized by small $a / d$. The beams with $a / d$ higher than $6(a / d \geqslant 6)$ are limited for all (NSC and HSC) beams; further research is therefore required to verify the found $p_{F}$.

The frequency distribution of the stirrup yielding strength $\left(f_{y w}\right)$ varies from $179 \mathrm{MPa}$ to $840 \mathrm{MPa}$. It is worth noting that $f_{y w}$ values are not equally distributed in the range from $300 \mathrm{MPa}$ to $500 \mathrm{MPa}$. A large amount of beams is characterized by 300 and $500 \mathrm{MPa}$. Thus, regarding the stirrup, these two values can be good representatives of typical yielding strengths of stirrups for existing buildings $(300 \mathrm{MPa})$ and more recent ones $(500 \mathrm{MPa})$. The database is characterized by percentage of $\rho_{w}$ that ranges from 0.040 to 1.750 with a large amount of beams characterized by 0.250 .

In order to determine a more accurate shear strength reduction factor for the shear design method, the change in the $\phi$ obtained from the analysis is compared in Table 1 for different values of $V_{f_{c}}$ and $p_{F}$. $\phi$ decreases as $\beta$ increases, and the reduction in the $\phi$ increases with $V_{f_{c}}$. For given $V_{f_{c}}$ and $p_{F}$, the $\phi$ for the HSC beams are found to be greater than the one for the NSC beams, so it can be inferred that the $\phi$ for HSC beams is more safe than the one for the NSC beams. In the ACI318 (1995), the $\phi$ considered in predicting the shear strength equals to 0.85 .

It is indicated that this value corresponds to the target values of $p_{F}=10^{-2}(\beta=2.33)$ and $V_{f_{c}}=0.10$. In the ACI318 (2002) and ACI318 (2011), the factor of 0.85 was replaced by a factor of 0.75 , which corresponds to the target values of $p_{F}=10^{-5}(\beta=4.27)$ and $V_{f_{c}}=0.10$ for all beams. It is observed that this value is conservative for $p_{F}>10^{-5}$ and a variation coefficient of 0.10. Ninety seven percent of the beams have strengths that exceed 0.75 times the calculated strength. The effects of $f_{c}, a / d, \rho_{w}$ and $f_{y w}$ on the $\phi$ are discussed below. 
Table 1. Changing the average values of $\phi$

\begin{tabular}{|c|c|c|c|c|c|c|c|}
\hline \multirow{2}{*}{$V_{f_{c}}$} & \multicolumn{6}{|c|}{$p_{F}$} & \multirow{2}{*}{ Beams } \\
\hline & $10^{-7}$ & $10^{-6}$ & $10^{-5}$ & $10^{-4}$ & $10^{-3}$ & $10^{-2}$ & \\
\hline 0.10 & 0.716 & 0.736 & 0.758 & 0.784 & 0.815 & 0.854 & \multirow{5}{*}{$\begin{array}{c}\text { NSC } \\
(281 \\
\text { beams })\end{array}$} \\
\hline 0.12 & 0.703 & 0.723 & 0.746 & 0.773 & 0.806 & 0.847 & \\
\hline 0.15 & 0.681 & 0.703 & 0.728 & 0.756 & 0.791 & 0.836 & \\
\hline 0.18 & 0.659 & 0.683 & 0.708 & 0.739 & 0.776 & 0.823 & \\
\hline 0.20 & 0.645 & 0.669 & 0.695 & 0.727 & 0.766 & 0.815 & \\
\hline 0.10 & 0.749 & 0.766 & 0.785 & 0.808 & 0.835 & 0.870 & \multirow{5}{*}{$\begin{array}{c}\text { HSC } \\
(94 \\
\text { beams })\end{array}$} \\
\hline 0.12 & 0.733 & 0.751 & 0.772 & 0.796 & 0.825 & 0.862 & \\
\hline 0.15 & 0.708 & 0.728 & 0.750 & 0.776 & 0.808 & 0.849 & \\
\hline 0.18 & 0.682 & 0.704 & 0.727 & 0.756 & 0.790 & 0.834 & \\
\hline 0.20 & 0.666 & 0.688 & 0.713 & 0.742 & 0.778 & 0.825 & \\
\hline 0.10 & 0.724 & 0.744 & 0.765 & 0.790 & 0.820 & 0.858 & \multirow{5}{*}{$\begin{array}{c}\text { NSC } \\
\text { and } \\
\text { HSC } \\
(375 \\
\text { beams) }\end{array}$} \\
\hline 0.12 & 0.710 & 0.730 & 0.753 & 0.779 & 0.810 & 0.851 & \\
\hline 0.15 & 0.688 & 0.709 & 0.733 & 0.761 & 0.795 & 0.839 & \\
\hline 0.18 & 0.665 & 0.688 & 0.713 & 0.743 & 0.780 & 0.826 & \\
\hline 0.20 & 0.650 & 0.674 & 0.700 & 0.731 & 0.769 & 0.817 & \\
\hline
\end{tabular}

(a)

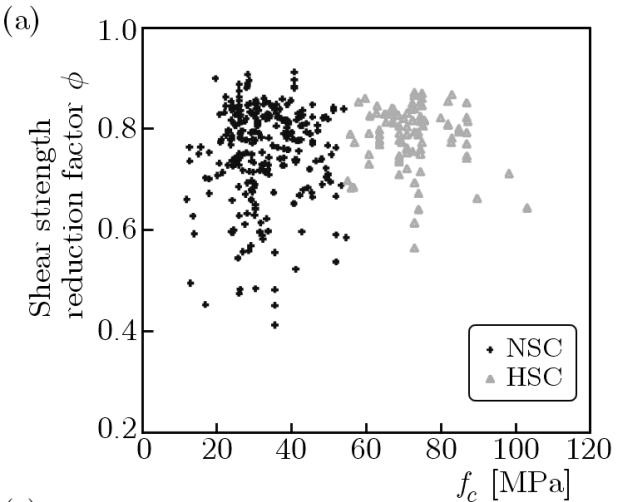

(c)

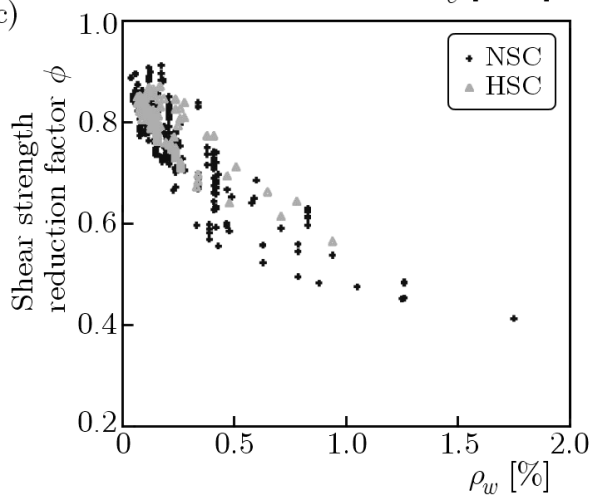

(b)

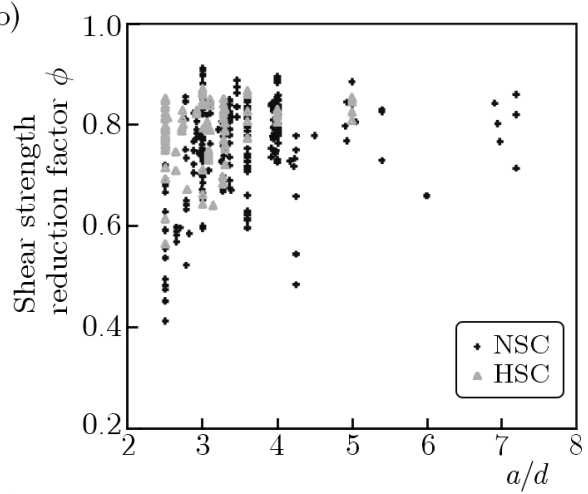

(d)

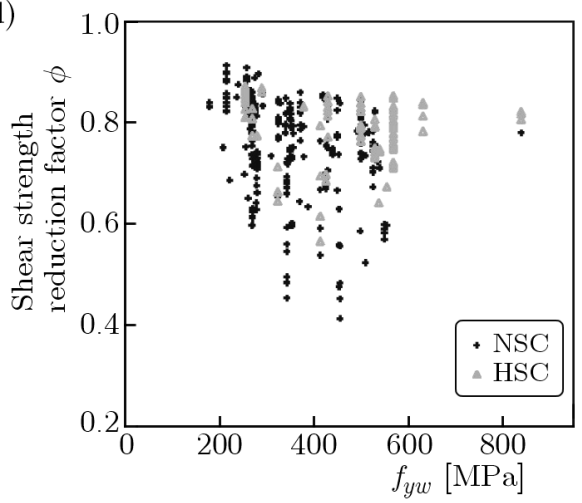

Fig. 2. Range of $\phi$ values determined using the evaluation database for $\beta=4.27$ and $V_{f c}=0.10$

Figures $2 \mathrm{a}$ and $3 \mathrm{a}$ show the variation of $\phi$ with $f_{c}$ for $\beta=4.27\left(p_{F}=10^{-5}\right), V_{f c}=0.10$ and $\beta=2.33\left(p_{F}=10^{-2}\right), V_{f c}=0.10$, respectively. The $\phi$ for the existing test data yields large scatter and is not influenced significantly by $f_{c}$ for all (NSC and HSC) beams. Figures $2 \mathrm{~b}$ and $3 \mathrm{~b}$ show the variation of $\phi$ with $a / d$ for $\beta=4.27\left(p_{F}=10^{-5}\right), V_{f c}=0.10$ and $\beta=2.33$ $\left(p_{F}=10^{-2}\right), V_{f c}=0.10$, respectively. The $\phi$ for the existing test data yields large scatter in the results for all (NSC and HSC) beams. 29\% of the NSC beam tests (81 of 281 tests) and only 
$11 \%$ of the HSC beam tests (10 of 94 tests) were conducted for $(a / d) \geqslant 4.0$. The corresponding $\phi$ of 13 of 81 NSC beams are less than 0.75 for $p_{F}=10^{-5}, V_{f c}=0.10$ and the corresponding $\phi$ of 11 of 81 NSC beams are less than 0.85 for $p_{F}=10^{-2}, V_{f c}=0.10$. The corresponding $\phi$ of HSC beams are higher than 0.75 for $p_{F}=10^{-5}, V_{f c}=0.10$ and 0.85 for $p_{F}=10^{-2}, V_{f c}=0.10$.
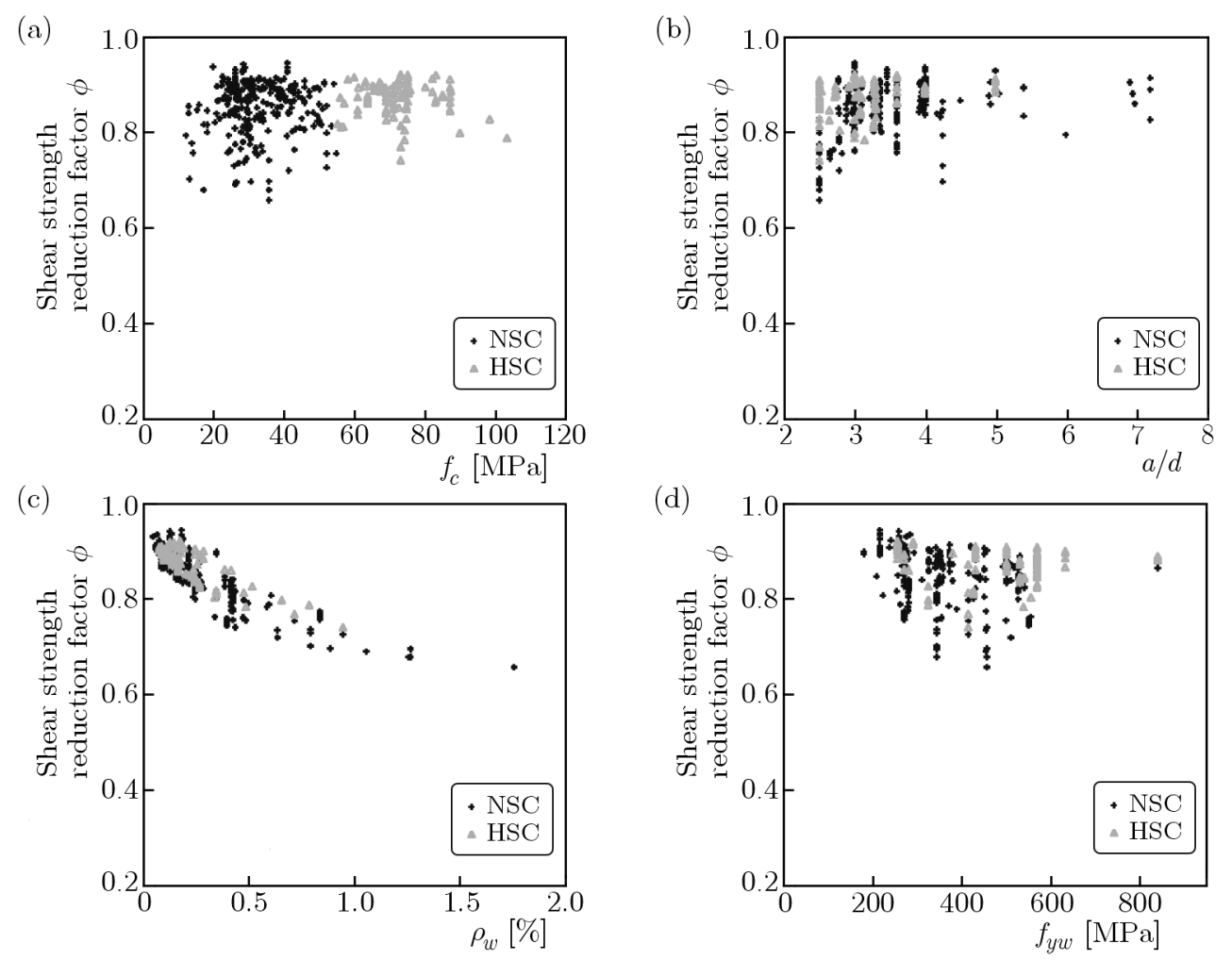

Fig. 3. Range of $\phi$ values determined using the evaluation database for $\beta=2.33$ and $V_{f c}=0.10$

Figures $2 \mathrm{c}$ and $3 \mathrm{c}$ show the variation of $\phi$ with the $\rho_{w}$ for $\beta=4.27\left(p_{F}=10^{-5}\right), V_{f c}=0.10$ and $\beta=2.33\left(p_{F}=10^{-2}\right), V_{f c}=0.10$, respectively. $10 \%$ of the NSC beam tests $(28$ of 281 tests) were conducted for $\rho_{w} \geqslant 0.5 \%$ and only $7 \%$ of the HSC beam tests (7 of 94 tests) were conducted for $\rho_{w} \geqslant 0.5 \%$. The corresponding $\phi$ of 28 NSC and 7 HSC beams are less than 0.75 for $p_{F}=10^{-5}, V_{f c}=0.10$ and less than 0.85 for $p_{F}=10^{-2}, V_{f c}=0.10$. It is observed that the $\phi$ decreases with increasing $\rho_{w}$ for all beams. Figures $2 \mathrm{~d}$ and $3 \mathrm{~d}$ show the variation of $\phi$ with $f_{y w}$ for $\beta=4.27\left(p_{F}=10^{-5}\right), V_{f c}=0.10$ and $\beta=2.33\left(p_{F}=10^{-2}\right), V_{f c}=0.10$, respectively. The $\phi$ for existing test data yields large scatter in the results for all (NSC and HSC) beams.

It can be stated that the $\phi$ values are not equally distributed with respect to $f_{c}, a / d$ and $f_{y w}$. The beams with $a / d$ higher than $6(a / d \geqslant 6.0)$ are limited for all (NSC and HSC) beams; further research is therefore required to verify the found $p_{F}$.

\section{Conclusions}

The change in the shear strength reduction factor according to the ACI318 is investigated for different coefficients of variation and failure probabilities. The following conclusions can be drawn from the results of this study.

- It is found that $\phi$ of 0.75 , which is a value recommended by the ACI318 (2002) and ACI318 (2011), corresponds to the target values of $p_{F}=10^{-5}(\beta=4.27)$ and $V_{f c}=0.10$, whereas $\phi$ of 0.85 , which is a value recommended by the ACI318 (1995), corresponds to the target values of $p_{F}=10^{-2}(\beta=2.33)$ and $V_{f c}=0.10$. 
- The values of $\phi$ for the considered beams are largely scattered and are not influenced significantly by $f_{c}, a / d$ and $f_{y w}$. The $\phi$ of HSC beams with $(a / d) \geqslant 4.0$ are higher than 0.75 for $p_{F}=10^{-5}, V_{f c}=0.10$ and 0.85 for $p_{F}=10^{-2}, V_{f c}=0.10$. The beams with $a / d$ higher than $6(a / d \geqslant 6.0)$ and with $\rho_{w} \geqslant 0.5 \%$ are limited for all (NSC and HSC) beams; further research is therefore required to verify the found $p_{F}$.

- It is observed that the $\phi$ decreases with increasing $\rho_{w}$ for all beams.

- For given $V_{f_{c}}$ and $p_{F}, \phi$ for the HSC beams are found to be greater than the one for the NSC beams, so it can be inferred that $\phi$ for the HSC beams is more safe than the one for the NSC beams.

\section{References}

1. Adebar P., Collins M.P., 1996, Shear strength of members without transverse reinforcement, Canadian Journal of Civil Engineering, 23, 1, 30-41

2. American Concrete Institute Committee 318 (ACI318), 1995, Building Code Requirements for Structural Concrete (ACI318M-95) and Commentary, Farmington Hills, MI

3. American Concrete Institute Committee 318 (ACI318), 2002, Building Code Requirements for Structural Concrete (ACI318M-02) and Commentary, Farmington Hills, MI

4. American Concrete Institute Committee 318 (ACI318), 2011, Building Code Requirements for Structural Concrete (ACI318M-11) and Commentary, Farmington Hills, MI

5. Anderson N.S., Ramirez J.A., 1989, Detailing of stirrup reinforcement, ACI Structural Journal, 86, $5,507-515$

6. Ang A.H.S., Tang W.H., 1984, Probability Concepts in Engineering Planning and Design. V.II - Decision, Risk, and Reliability, Wiley, New York

7. Angelakos D., Bentz E.C., Collins M.P., 2001, Effect of concrete strength and minimum stirrups on shear strength of large members, ACI Structural Journal, 98, 3, 290-300

8. ASCE-ACI426, 1973, The shear strength of reinforced concrete members, Proceedings of the American Society of Civil Engineers, 99, ST6, 1091-1187

9. AS5104-2005, General Principles on Reliability for Structures, Standards Australia, Sydney

10. ASCE-SEI, 2010, Minimum design loads for buildings and other structures - ASCE/SEI7-10

11. BAHL N.S., 1968, On the effect of beam depth to shear strength of simply supported reinforced concrete beams with and without shear reinforcement, PhD. Dissertation, Universität Stuttgart, Germany, $125 \mathrm{p}$.

12. Beck A.T., Oliveira W.L.A., DeNardim S., ElDebs A.L.H.C., 2009, Reliability-based evaluation of design code provisions for circular concrete-filled steel columns, Engineering Structures, 31, 2299-2308

13. Bresler B., Scordelis A.C., 1961, Shear strength of reinforced concrete beams, Structures and Materials Research, 100, 3, Dept. of Civil Engineering, University of California, Berkeley, USA

14. Bresler B., Scordelis A.C., 1966, Shear strength of reinforced concrete beams - Series III. Report No. 65 -10, Structures and Materials Research, University of California, Berkeley, USA

15. Cladera A., Mari A.R., 2005, Experimental study on high-strength concrete beams failing in shear, Engineering Structures, 27, 10, 1519-1527

16. Cladera A., Mari A.R., 2007, Shear strength in the new Euro code 2. A step forward?, Structural Concrete, 8,2, 57-66

17. Collins M.P., Kuchma D., 1999, How safe are our large, lightly reinforced concrete beams, slabs and footings? ACI Structural Journal, 96, 4, 482-490 
18. Cucchiara C., La Mendola L., Papia M., 2004, Effectiveness of stirrups and steel fibres as shear reinforcement, Cement and Concrete Composites, 26, 7, 777-786

19. Ellingwood B., 1978, Reliability basis of load and resistance factors for reinforced concrete design, Building Science Series, 110, National Bureau of Standards, Washington, D.C

20. Elzanaty A.H., Nilson A.H., Slate F.O., 1986, Shear capacity of reinforced concrete beams using high strength concrete, ACI Structural Journal, 83, 2, 290-296

21. Enright M.P., Frangopol D.M., 1998, Probabilistic analysis of resistance degradation of reinforced concrete bridge beams under corrosion, Engineering Structures, 20, 960-971

22. Gonzalez F.B., 2002, Concrete with recycled aggregates from demolition: dosing, nechanical properties and shear behavior, PhD Thesis, Universidad de la Coruna

23. Guralnick S.A., 1960, High-strength deformed steel bars for concrete reinforcement, ACI Journal, Proceedings, 57, 3, 241-282

24. Haddadin M.J., Hong S.T., Mattock A.H., 1971, Stirrup effectiveness in reinforced concrete beams with axial force, Proceedings ASCE, 97, ST9, 2277-2297

25. Hao H., Stewart M.G., Li Z.-X., Shi Y., 2010, RC column failure probabilities to blast loads, International Journal of Protective Structures, 1, 4

26. Hasofer A.M., Lind N.C., 1974, An exact and invariant first order reliability format, Journal of the Engineering Mechanics Division, ASCE, 100, 111-121

27. Hognestad E., 1951, A study of combined bending and axial load in reinforced concrete members, Engineering Experiment Station Bulletin, 399, University of Illinois, Urbana

28. Hosseinnezhad A., Pourzeynali S., Razzaghi J., 2000, Aplication of first-order secondmoment level 2 reliability analysis of presstressed concrete bridges, 7th International Congress on Civil Engineering

29. ISO2394, 1998, General Principles on Reliability for Structures, International Organization for Standardization, Geneva

30. JCSS, 2000, Probabilistic model code Part III, Joint Committee on Structural Safety

31. Johnson M.K., Ramirez J.A., 1989, Minimum shear reinforcement in beams with higher strength concrete, ACI Structural Journal, 86, 4, 376-382

32. Karayiannis C.G., Chalioris C.E., 1999, Experimental investigation of the influence of stirrups on the shear failure mechanism of reinforced concrete beams (in Greek), Proceedings of 13th Hellenic Conference on Concrete, Rethymnon, Greece, 1, 133-141

33. Kong P.Y.L., Rangan B.V., 1998, Shear strength of high-performance concrete beams, ACI Structural Journal, 95, 6, 677-688

34. Krefeld W.J., Thurston C.W., 1966, Studies of the shear and diagonal tension strength of simply supported reinforced concrete beams, ACI Journal, 63, 4, 451-476

35. LEE J.Y., Kim U.Y., 2008, Effect of longitudinal tensile reinforcement ratio and shear span-depth ratio on minimum shear reinforcement in beams, ACI Structural Journal, 105, 2, 134-144

36. Leonhardt F., Walther R., 1962, Schubversuche an einfeldrigen Stahlbetonbalken mit und ohne Schubbewehrung (Shear tests of single span RC beams with and without stirrups), Deutscher Ausschuss für Stahlbeton, 151

37. Low H.Y., HaO H., 2001, Reliability analysis of reinforced concrete slabs under explosive loading, International Journal of Structural Safety, 23, 2, 157-178

38. MaCGregor J.G., 1983, Load and resistance factors for concrete design, ACI Journal, 80, 279-287

39. Madsen H.O., Krenk S., Lind N.C., 1986, Methods of Structural Safety, Prentice-Hall

40. Mattock A.H., WAng Z., 1984, Shear strength of reinforced concrete members subject to high axial compressive stress, ACI Structural Journal, 11, 3, 287-298 
41. McGormley J.C., Creary D.B., Ramirez J.A., 1996, The performance of epoxy-coated shear reinforcement, ACI Structural Journal, 93, 5, 531-537

42. Melchers RE., 1999, Structural Reliability Analysis and Prediction, John Wiley \& Sons

43. Mirza S.A., 1996, Reliability-based design of reinforced concrete columns, Structral Safety, 18, $2 / 3,179-194$

44. Mirza S.A., Hatzinikolas M., MacGregor, J.G., 1979, Statistical descriptions of strength of concrete, Journal of the Structural Division, ASCE, 105, ST6, 1021-1037

45. Mirza S.A., MacGregor J.G., 1979a, Variability of mechanical properties of reinforcing bars, Journal of the Structural Division, ASCE, 105, ST5, 921-937

46. Mirza S.A., MacGregor J.G., 1979b, Variations in dimensions of reinforced concrete members, Journal of the Structural Division, ASCE, 105, ST4, 751-766

47. Mphonde A. G., Frantz G.C., 1985, Shear tests of high- and low-strength concrete beams with stirrups, High Strength Concrete, SP-87, ACI, Detroit, 179-196

48. NBR8800:2008, Design of Steel and Steel-Concrete Composite Structures: Procedures. ABNT Brazilian Association of Technical Codes, Rio de Janeiro (in Portuguese)

49. Neves R.A., Chateauneuf A.M., Venturini W.S., 2008, Component and system reliability analysis of nonlinear reinforced concrete grids with multiple failure modes, Structural Safety, 30, 3, 183-189

50. NowAK A., Szerszen M., 2003, Calibration of design code for buildings (ACI318): Part 1 statistical models for resistance, ACI Structural Journal, 100, 377-382

51. Oliveira W.L., Beck A.T., ElDebs A.L.H.C., 2008, Safety evaluation of circular concrete-filled steel columns designed according to Brazilian building code NBR 8800:2008, IBRACON Structures and Materials Journal, 1, 212-236

52. Ostlund L., 1991, An estimation of T-values, [In:] Reliability of Concrete Structures. CEB Bulletin d'Information, 202, Lausanne, Switzerland

53. Ozcebe G., Ersoy U., Tankut T., 1999, Evaluation of minimum shear reinforcement requirements for higher strength concrete, ACI Structural Journal, 96, 3, 361-368

54. Palakas, M.N., Darwin, D., 1980, Shear strength of lightly reinforced concrete beams, Structural Engineering Materails Report, 3, University of Kansas Center for Research, $198 \mathrm{p}$

55. Placas A., Regan P.E., 1971, Shear failure of reinforced concrete beams, ACI Journal, 68, 10, 763-773

56. RackWitz R., Fiessler B., 1978, Structural reliability under combined random load sequences, Computers and Structures, 9, 5, 489-494

57. Rajagopalan, K.S., Ferguson, P.M., 1968, Exploratory shear tests emphasizing percentage of longitudinal steel, ACI Journal, Proceedings, 65, 8, 634-638

58. Ramsay R.J., Mirza S.A., MacGregor J.G., 1979, Monte Carlo study of short time deflections of reinforced concrete beams, ACI Journal, Proceedings, 76, 8, 897-918

59. Ranganathan R., 1990, Reliability Analysis and Design of Structures, McGraw-Hill, New Delhi

60. Ribeiro S.E.C., Diniz S.M.C., 2013, Reliability-based design recommendations for FRP-reinforced concrete beams, Engineering Structures, 52, 273-283

61. Roller J.J., Russell, H.G., 1990, Shear strength of HSC beams with web reinforcement, ACI Structural Journal, 87, 2, 191-198

62. Sarzam K.F., Al-Musawi J.M.S., 1992, Shear design of high-and normal-strength concrete beams with web reinforcement, ACI Structural Journal, 89, 6, 658-664

63. Shin S.W., Lee K.S., Moon J., Ghosh S.K., 1999, Shear strength of reinforced high-strength concrete beams with shear span-to-depth ratios between 1.5 and 2.5, ACI Structural Journal, 96, 4, 549-556 
64. Soares R.C., Mohammed A., Venturini W.S., Lemaire M., 2002, Reliability analysis of nonlinear reinforced concrete frames using the response surface method, Reliability Engineering and System Safety, 75, 1-16

65. Swamy R.N., Andriopoulos A.D., 1974, Contribution of aggregate interlock and dowel forces to the shear resistance of reinforced beams with web reinforcement, Shear in Reinforced Concrete, SP-42, ACI, Mich., 129-166

66. TAn K., Kong F., Teng S., Weng L., 1997, Effect of web reinforcement on high strength concrete deep beams, ACI Journal, 94, 5, 572-582

67. TS500, 2000, Requirements for design and construction of reinforced concrete structures, Ankara, Turkish Standards Institute (in Turkish)

68. Xie Y., Ahmad S. H., Yu T., Hino S., Chung W., 1994, Shear ductility of reinforced concrete beams of normal and high-strength concrete, ACI Structural Journal, 91, 2, 140-149

69. Val D., Bluuger F., Yankelevsky D., 1997, Reliability evaluation in nonlinear analysis of reinforced concrete structures, Structural Safety, 19, 2, 203-217

70. VAl D.V., Chernin L., 2009, Serviceability reliability of reinforced concrete beams with corroded reinforcement, Journal of Structural Engineering, ASCE, 135, 8, 896-905

71. Vrouwenvelder A.C.W.M., 2002, Developments towards full probabilistic design codes, Structural Safety, 24, 2/4, 417-432

72. Yoon Y., Cook W.D., Mitchell D., 1996, Minimum shear reinforcement in normal-, medium-, and high-strength concrete beams, ACI Structural Journal, 93, 5, 576-584

73. ZARARis P.D., PAPAdAKIS G., 1999, Influence of the arrangement of reinforcement on the shear strength of RC beams (in Greek), Proceedings of 13th Hellenic Conference on Concrete, I, Greece, 110-119

74. ZARARIS P.D., 2003, Shear strength and minimum shear reinforcement of reinforced concrete slender beams, ACI Structural Journal, 100, 2, 203-214 